\title{
Catalytic Activity of $\mathrm{Zr}^{4+} / \mathrm{ZA}$ on The Isomerization Reaction of $\alpha$-Pinene and It's Reusability Test
}

\author{
Nico Aditya Wijaya, Nanik Wijayati and Edy Cahyono \\ Chemistry Departement, FMIPA, Universitas Negeri Semarang \\ D6 Building, Sekaran, Gunungpati, Phone. (024) 8508112 Semarang 50229 \\ e-mail: nicoadityawijaya@gmail.com
}

Received: 20 September 2015, Revised: 30 February 2016, Accepted: 26 August 2016

\begin{abstract}
Production of turpentine oil from pine resin until December $2014^{\text {th }}$ was reported to reaching 17.150 tones with the wide of pine forest is $876.992,66$ acres. The main component of turpentine oil is $\alpha$-pinena which isomer products have high value for industrial raw materials. Effects concentration of impregnation and reusability test a best catalyst on $\alpha$-pinene isomerization reaction using catalysts $\mathrm{Zr}^{4+} /$ natural zeolite in which modificated with different $\mathrm{Zr}^{4+}$ concentration were analyzed. Characterization of catalyst included X-ray Fluoroscent for detection of $\mathrm{Zr}$ concentration in natural zeolites, Surface Area Analyzer for determine catalyst porosity using BET method, and determination of acidity using vapor ammonia and pyridine base adsorption gravimetric method. Isomerization process used a batch reactor with variation in the concentrations of $\mathrm{Zr}^{4+}$ impregnations 10,15 , and $20 \mathrm{w} / \mathrm{w}$ as well as reusability test used best catalyst. The highest conversion of $\alpha$-pinene used $\mathrm{Zr}^{4+} / \mathrm{ZA} 10 \%$ catalyst was $3,89 \%$ so as $\mathrm{Zr}^{4+} / \mathrm{ZA}^{10} \%$ catalyst is best catalyst than other catalysts whereas highest conversion of $\alpha$-pinene used $\mathrm{Zr}^{4+} / \mathrm{ZA} 10 \%$ regeneration catalyst was $4,26 \%$. The product is produced from isomerization reaction of $\alpha$-pinene used $\mathrm{Zr}^{4+} / \mathrm{ZA}$ all variations catalysts was camphene and limonene.
\end{abstract}

Keywords: $\mathrm{Zr}^{4+} /$ natural zeolyts, concentration of impregnation, catalyst resability, isomerization, $\alpha$-pinene

\section{INTRODUCTION}

Turpentine is one of the flagship products of non-timber PT. Perhutani in Indonesia. Production of turpentine oil from pine resin to December 2012, reported to reach 17.150 tonnes with an area of about 876.992,66 hectares of pine forest. The international market price of turpentine reach US $\$ 2,000$ per ton.minyak turpentine is used as raw material for the cosmetics industry, oil paint, a mixture of solvents, antiseptics, camphor and pharmaceuticals. The main component of turpentine oil are a-pinene. Indonesia turpentine oil contains about $57-86 \%$ a-pinene, $8-12 \%$ 3 -carene and other groups monoterpenes with a number of minor

The isomerization reaction can produce one or more products of isomeric compounds such materials. $\alpha$-Pinene isomerization reactions can be performed using a Lewis acid catalyst.
Acid catalyzed isomerization of alkenes can take place because of the migration of the double bond in the ring or chain. $\alpha$-Pinene transformation into a derivative compounds are new findings that involve changes in the structure is very complex but can occur in conditions quite easy and can increase the added value of the use of turpentine oil

Acid catalysts and homogeneous catalysts have a negative impact in the form of a large number of hazardous acid waste, also has shortcomings because it is difficult to separate from product. Given the environmental safety and economic reasons, there is a continuing effort to replace the conventional acid catalysts with solid acid catalysts newer heterogeneous. Heterogeneous catalysts can be used as an alternative with positive opportunities related to increased yields and selectivity of the process through the $\alpha$-pinene isomerization reaction 
(Severino, 1996). Advantages of heterogeneous catalysts are an environmentally friendly, noncorrosive, easily separated from the product by filtration, and can be used repeatedly in the long term. Additionally, heterogeneous catalysts increase the purity results because of side reactions can be eliminated. Another advantage is the use of a heterogeneous catalyst catalyst can be separated by filtration of the product when the reaction has been completed.

Based on the research Grzona (1999) using sulfated Zirconia as a catalyst preformance $\alpha$-pinene isomerization reaction to produce $\alpha$-pinene conversion of $17 \%-90 \%$. So this research, the authors tried to employ the use of metal $\mathrm{Zr}$ in the form of a heterogeneous catalyst $\mathrm{Zr}^{4+} / \mathrm{ZA}$ towards isomerization $\alpha$-pinene. The method used in dropped $\mathrm{Zr}$ against natural zeolite is a method of impregnation. In addition the catalyst is expected to be used again after the previous regenerated in order to minimize waste in the $\alpha$-pinene isomerization reaction.

\section{EXPERIMENTAL PROCEDURES}

Tools used include: a 100 mesh sieve, vacuum pump, stirrer hotplate, oven, a set of distillation, and a set of tools reflux, GC Hawllett Packard 5890 Series II, GC-MS Shimadzu QP 5000, SAA Quantachrome ASiQwin 1:11, PANalytical XRF MiniPal 4 , and FT-IR spectrophotometer Shimadzu FT-IR 8201 PC.

Setting instrument on Gas Chromatography (GC) with a column HP-5-nonpolar semipolar nature. Samples were analyzed by GC instrument conditions at a temperature of $270^{\circ} \mathrm{c}$ injector, column temperature $80^{\circ} \mathrm{C}$, a temperature of $300^{\circ} \mathrm{C}$ detector and analysis is performed for 20 minutes. As for knowing the product compounds using gas chromatography-mass spectrophotometer (GCMS).Conditions of GC-MS instruments when used for the analysis the same as the conditions on the GC. On the Surface Area Analyzer mass setting $0.1345 \mathrm{~g}$ sample was analyzed with a maximum time of 3 hours using $\mathrm{N}_{2}$ gas with the Press. Tolerance 0,050 / 0,050 (adsorption / desorbsi).At XrayFluoresenct setting $20.00 \mathrm{kV}, 147 \mathrm{uA}$ and Air 60 seconds.

Materials used: turpentine oil, distilled water, aquademin, natural zeolite (Malang), $\mathrm{AgNO}_{3}, \mathrm{HCl}, \mathrm{NH}_{4} \mathrm{Cl}, \mathrm{HF}$ with pro analyst Merck grade anhydrous $\mathrm{Na}_{2} \mathrm{SO}_{4}$, and the $\mathrm{N}_{2}$ gas from the PT. Samator.

Catalyst preparation and activation process begins with washing process natural zeolite with distilled water at room temperature three times and then dikeringkn in an oven at a temperature of $120^{\circ} \mathrm{C}$ for 3 hours. Then do the activation process and dealuminated natural zeolite with a soaking solution of $\mathrm{HF}, \mathrm{HCl}$ and $\mathrm{NH}_{4} \mathrm{Cl}$ (Trisunaryanti et al, 2005 modified).

Natural zeolite soaked with $1 \%$ HF solution for 30 minutes, then washed with aquademin. Then dried in an oven at a temperature of $120^{\circ} \mathrm{C}$ for 3 hours, then smoothed back. Natural zeolite that has been soaked HF, then soaked with $2 \mathrm{M}$ $\mathrm{HCl}$ solution for 1 hour. Then wash the natural zeolite with $\mathrm{HCl}$ immersion results aquademin until $\mathrm{Cl}$ ions disappear (test with $\mathrm{AgNO}_{3} 1 \%$ ). Then dry zeolite ion $\mathrm{Cl}$ outdoors in an oven at a temperature of $120^{\circ} \mathrm{C}$ for 3 hours and smoothed back. Furthermore, acid-activated natural zeolite soaked with a solution of $1 \mathrm{M} \mathrm{NH}_{4} \mathrm{Cl}$ for 1 day. Then washed with aquademin until $\mathrm{Cl}^{-}$ions disappear (test with $\mathrm{AgNO}_{3} 1 \%$ ). Then dried in an oven at a temperature of $120^{\circ} \mathrm{C}$ for 3 hours.

Natural zeolites are then calcined at a temperature of $400^{\circ} \mathrm{C}$ for 4 hours in a calcining furnace with nitrogen gas purged $10 \mathrm{~mL} / \mathrm{min}$. Furthermore, natural zeolite impregnated with a zirconium metal zirconium metal concentrations as much as 10,15 and $20 \%(\mathrm{w} / \mathrm{w})$ followed 
calcination back at $400^{\circ} \mathrm{C}$ temperature for 4 hours.

The catalyst has been activated and modified later used for $\alpha$-pinene isomerization reaction. The reaction was performed in a batch reactor with stirring and temperature control. $10 \mathrm{~mL}$ of $\alpha$-pinene included in the three-neck flask and heated to a temperature of $140^{\circ} \mathrm{C}$ then added $0.5 \mathrm{~g}$ of catalyst $\mathrm{Zr}^{4+} / \mathrm{ZA} 10 \%$ without added solvent. The reaction is run for 90 minutes. Furthermore, the product solution is separated by centrifugation for $15 \mathrm{~min}$. The next step is to repeat the same stages of the reaction catalyst for variations $\mathrm{Zr}^{4+} / \mathrm{ZA} 15 \%$ and $20 \% \mathrm{w} / \mathrm{w}$. Repetition of the reaction is also carried out at the time variations among others: 180 and 270 minutes and the catalyst with the results of the largest conversion of $\alpha$-pinene is regenerated and reused for the reaction. Results were analyzed using GC and GCMS for best results.

\section{RESULT AND DISCUSSION}

Natural zeolite that has gone through the process of washing with distilled water soaked with HF $1 \%$. The goal of immersion is damaging the framework of the zeolite so that more structured. It also eliminates Si outside the framework and also dissolves impurities such as $\mathrm{CaO}, \mathrm{MgO}$, and $\mathrm{K}_{2} \mathrm{O}$. Then the zeolite is treated with $2 \mathrm{M} \mathrm{HCl}$ soaked functioning dissolve the constituent metals such as Fe zeolite thus more open pore zeolites and zeolite more stable.

Furthermore immersion using $\mathrm{NH}_{4} \mathrm{Cl}$ solution that aims to replace the cations balancing the zeolite framework such as $\mathrm{Na}^{+}$ and $\mathrm{Ca}^{2+}$ by $\mathrm{NH}_{4}^{+} \cdot \mathrm{NH}_{4} \mathrm{Cl}$ salt is used as a cation exchanger because $\mathrm{NH}_{4} \mathrm{Cl}$ susceptible to ionizing be exchanged with $\mathrm{NH}_{4}^{+}$and $\mathrm{Na}^{+}$and $\mathrm{Ca}^{2+}$ to form $\mathrm{NH}_{4} / \mathrm{ZA}$ which is then calcined to form the $\mathrm{N}_{2}$ gas $\mathrm{H} / \mathrm{ZA}$ thus having Brønsted acids and facilitate dropped metal.
Impregnation performed by immersion in a solution of $\mathrm{ZrCl}_{4}$ natural zeolite while stirring with a magnetic stirrer and heated at a temperature of $90^{\circ} \mathrm{C}$ on a hotplate. This process aims to attach the active form $\mathrm{Zr}^{4+}$ metal ions to the surface of the solid zeolite. Furthermore, the calcination at a temperature of $400^{\circ} \mathrm{C}$ for 4 hours to remove the water and organic impurities which may contaminate during the process of impregnation.

Having obtained the catalyst $\mathrm{Zr}^{4+} / \mathrm{ZA} 10$, 15 and $20 \%$ analysis by X-Ray Fluoroscent (XRF) to see how the content of $\mathrm{Zr}$ is managed on the natural zeolite. Zr metal analysis results in the $\mathrm{H} / \mathrm{ZA}$ and $\mathrm{Zr}^{4+} / \mathrm{ZA}$ catalyst is presented in Table 1.

Table 1. Composition of Zr Metal in H/ZA and Catalyst

\begin{tabular}{cc}
\hline Catalyst & Consentration of $\mathrm{Zr}(\%)$ \\
\hline $\mathrm{H} / \mathrm{ZA}$ & - \\
$\mathrm{Zr}^{4+} / \mathrm{ZA} 10 \%$ & $11 \%$ \\
$\mathrm{Zr}^{4+} / \mathrm{ZA} 15 \%$ & $6,8 \%$ \\
$\mathrm{Zr}^{4+} / \mathrm{ZA} 20 \%$ & $4,6 \%$ \\
$\mathrm{Zr}^{4+} / \mathrm{ZA} 10 \%$ regeneration & $7,1 \%$ \\
\hline
\end{tabular}

The dropped $\mathrm{Zr}$ metal on zeolite experiencing decrease efficiency dropped metal. The greater the $\mathrm{Zr}$ metal to be entrusted even smaller $\mathrm{Zr}$ dropped successful, it is likely due to the limitations of the zeolite cavity to accommodate the metal so that the metal - the metal does not enter into the cavity of the zeolite but spread to the surface of solids (Trisunaryanti et al., 2005 ). Another cause likely due to poor impregnation process so that the metal is not spread evenly $\mathrm{Zr}$ and $\mathrm{Zr}$ metal is also a possibility that falls in excess of $10 \% \mathrm{w} / \mathrm{w}$ to experience saturation concentration so it can not stick to. While the catalyst $\mathrm{Zr}^{4+} / \mathrm{ZA} 10 \%$ regenerated metal content decreased to $7.1 \%$, this is likely due to the metal separated from the zeolite or undergo sintering due to contact with the reactants are $\alpha$-pinene. 
Acidity test on the research done by ammonia gas adsorption and pyridine, then calculated the number of mmol each adsorbed gas. Results of ammonia gas adsorption and pyridine are presented in Table 2.

Table 2.Acidity Value in $\mathrm{H} / \mathrm{ZA}$ and $\mathrm{Zr}^{4+} / \mathrm{ZA}$ Catalyst

\begin{tabular}{ccc}
\hline \multirow{2}{*}{ Sample } & \multicolumn{2}{c}{ Acidity $(\mathrm{mmol} / \mathrm{g})$} \\
\cline { 2 - 3 } & $\begin{array}{c}\text { Total } \\
\text { (Ammonia) }\end{array}$ & $\begin{array}{c}\text { Surface } \\
\text { (Pyridine) }\end{array}$ \\
\hline $\mathrm{H} / \mathrm{ZA}$ & 6,7437 & 0,7618 \\
$\mathrm{Zr}^{4+} / \mathrm{ZA} \mathrm{10 \%}$ & 3,2847 & 0,6302 \\
$\mathrm{Zr}^{4+} / \mathrm{ZA} \mathrm{15 \%}$ & 2,2834 & 0,3788 \\
$\mathrm{Zr}^{4+} / \mathrm{ZA} 20 \%$ & 1,7261 & 0,1708 \\
$\mathrm{Zr}^{4+} / \mathrm{ZA} \mathrm{10 \%}$ & 3,4436 & 0,5215 \\
regeneration & & \\
\hline
\end{tabular}

In theory, dropped metals can add sites Lewis acid is the acid because the metal, in this case the metal $\mathrm{Zr}$ have empty $d$ orbitals. However, the results of this test showed that the value of total acidity and good acidity on the surface of H/ZA higher than $\mathrm{Zr}^{4+} / \mathrm{ZA}$. This is probably less evenly distributed $\mathrm{NH}_{3}$ gas and pyridine adsorption by the catalyst due to accumulation of metals $\mathrm{Zr}$ or less good due to the adsorption process is carried catalyst. On the catalysts $\mathrm{Zr}^{4+} / \mathrm{ZA} 10 \%$ regeneration value reduced due to surface acidity of catalyst deactivated due to react, but with a different total acidity where values rise. This was probably dropped metal more evenly spread and does not clog your pores so that ammonia is adsorbed to the catalyst pores. FTIR testing is then performed to see Lewis acid and Brønsted acid catalyst. IR spectra readings are presented in Figure 1.

According Ryczkowski (2001) in Amilia (2013) suggested characteristics Brønsted acid will appear at the wave numbers 1550 and 1640 $\mathrm{cm}-1$. On-IR spectrophotometer reading all of the catalyst and the H/ZA has the uptake. Means signifies that the catalyst has an Brønsted acid sites. While Lewis acid due to the result of the metals $\mathrm{Zr}$, -OH shown reduced absorption area wavenumber $3672.47 \mathrm{~cm}-1$ in H/ZA 63.004 which was read on the catalyst $\mathrm{Zr}^{4+} / \mathrm{ZA} 10 \%$ to 48.083 , the $\mathrm{Zr}^{4+} / \mathrm{ZA} 15 \%$ to 55,6 and on $\mathrm{Zr}^{4+} / \mathrm{ZA} 20 \%$ to 50.822 . This is consistent with the proposed Comelli et al (2006), namely the addition of a metal in a material will show the changes in absorption-OH thereby indicating Lewis acid with the $\mathrm{OH}$ absorbance changes.

From the analysis results obtained BET average pore is increased while the specific surface area and pore volume of the catalyst

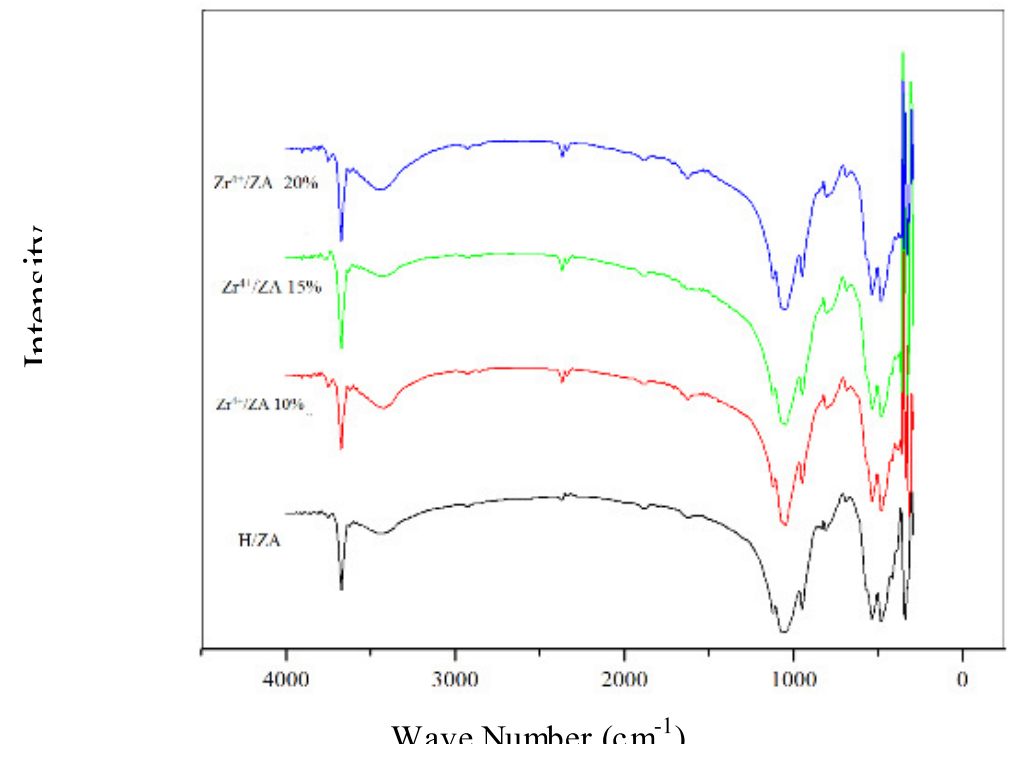

Figure 1. IR spectra readings in Catalyst and $\mathrm{H} / \mathrm{ZA}$ 
Table 3.Results of measuring wide spesific surface, average pore sizes, and total pore volume catalyst

\begin{tabular}{cccc}
\hline Catalyst & $\begin{array}{c}\text { Wide Spesific } \\
\text { Surface }\left(\mathrm{m}^{2} / \mathrm{g}\right)\end{array}$ & $\begin{array}{c}\text { Average } \\
\text { Pore } \\
\text { Sizes }(\AA ́)\end{array}$ & $\begin{array}{c}\text { Pore } \\
\text { Volume } \\
(\mathrm{cc} / \mathrm{g})\end{array}$ \\
\hline $\mathrm{H} / \mathrm{ZA}$ & 23,27471 & 157,7 & $2,374 \times 10^{-2}$ \\
$\mathrm{Zr}^{4+} / \mathrm{ZA} 10 \%$ & 23,38008 & 163,8 & $2,544 \times 10^{-2}$ \\
$\mathrm{Zr}^{4+} / \mathrm{ZA} 10 \%$ & 11,69863 & 248,6 & $2,033 \times 10^{-2}$ \\
Regeneration & 11,696 \\
\hline
\end{tabular}

regeneration decreases, it is appropriate according to Trisunaryanti, et al (2002). But unlike the statement that should once regenerated surface area and pore volume increases. This is likely due to less successful regeneration process carried out due to lack of net remove any remaining $\alpha$-pinene and calcination process without the use of $\mathrm{O}_{2}$ and $\mathrm{H}_{2}$ gas so that organic impurities did not disappear completely.

Compounds contained in the results of isomerization reaction $\alpha$-pinene with $\mathrm{H} /$ $\mathrm{ZA}$ for comparison and catalyst $\mathrm{Zr}^{4+} / \mathrm{ZA}$ with each reaction time was analyzed by gas chromatography and to determine the compounds contained products were analyzed by gas chromatography-spectrophotometer mass and spectrophotometer-IR to determine Gugsa compound function. Results from a reading of gas chromatography-mass spectrophotometer (GCMS) products isomerization and interpretation presented in Figure 2 and Table 4.

Tabel 4. GCMS interpretation spectrum of isomerization product

\begin{tabular}{cc}
\hline Peak & compound \\
\hline 1 & $\alpha$-pinena \\
2 & Kamfena \\
3 & $\beta$-pinena \\
4 & 3 -karena \\
5 & p-simena \\
6 & Limonena \\
\hline
\end{tabular}

The reading of the results of the isomerization product functional group-IR spectrophotometer (FTIR) is presented in Figure 3 and Table 5.

Tabel 5.IR interpretation spectrum product of $\alpha$-pinene isomerization

\begin{tabular}{cll}
\hline No & \multicolumn{1}{c}{ Wave Number $\left(\mathrm{cm}^{-1}\right)$} & \multicolumn{1}{c}{ Interpretation } \\
\hline 1 & $2924,09-2839,22$ & $\mathrm{C}-\mathrm{H}$ alkena group \\
2 & 2723,49 & $-\mathrm{CH}_{2}-$ alkyl group \\
3 & 1373,32 & $\mathrm{CH}_{3}$ group \\
4 & 879,54 & $\mathrm{C}=\mathrm{C}$ group \\
\hline
\end{tabular}

IR-spectrophotometer readings obtained isomerization product absorption peak at $2723.49 \mathrm{~cm}-1$ and $879.54 \mathrm{~cm}-1$ which indicate an alkyl group $\mathrm{CH}_{2}$ and $\mathrm{C}=\mathrm{C}$ at the outer ring because in-IR spectrophotometer readings of the isolated $\alpha$-pinene is not obtained $\mathrm{CH}_{2}$ uptake alkyl and $\mathrm{C}=\mathrm{C}$ on the outside of the ring

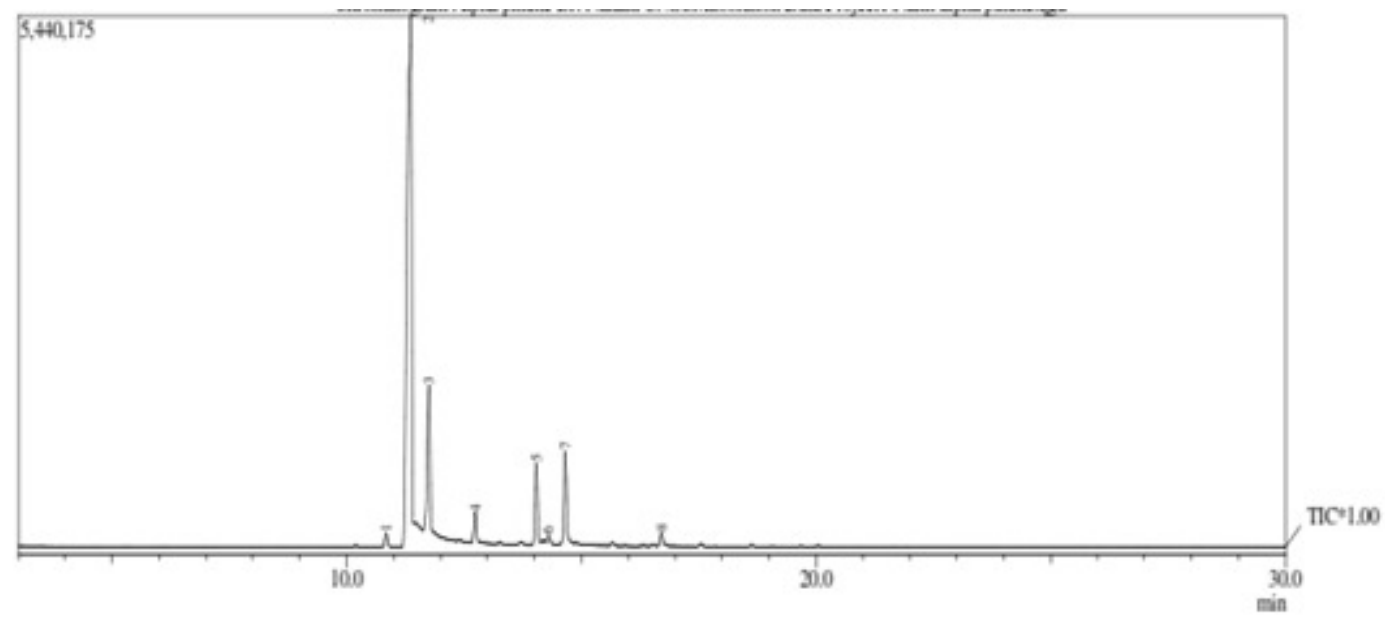

Gambar 2.GCMS kromatogram of isomerization product 


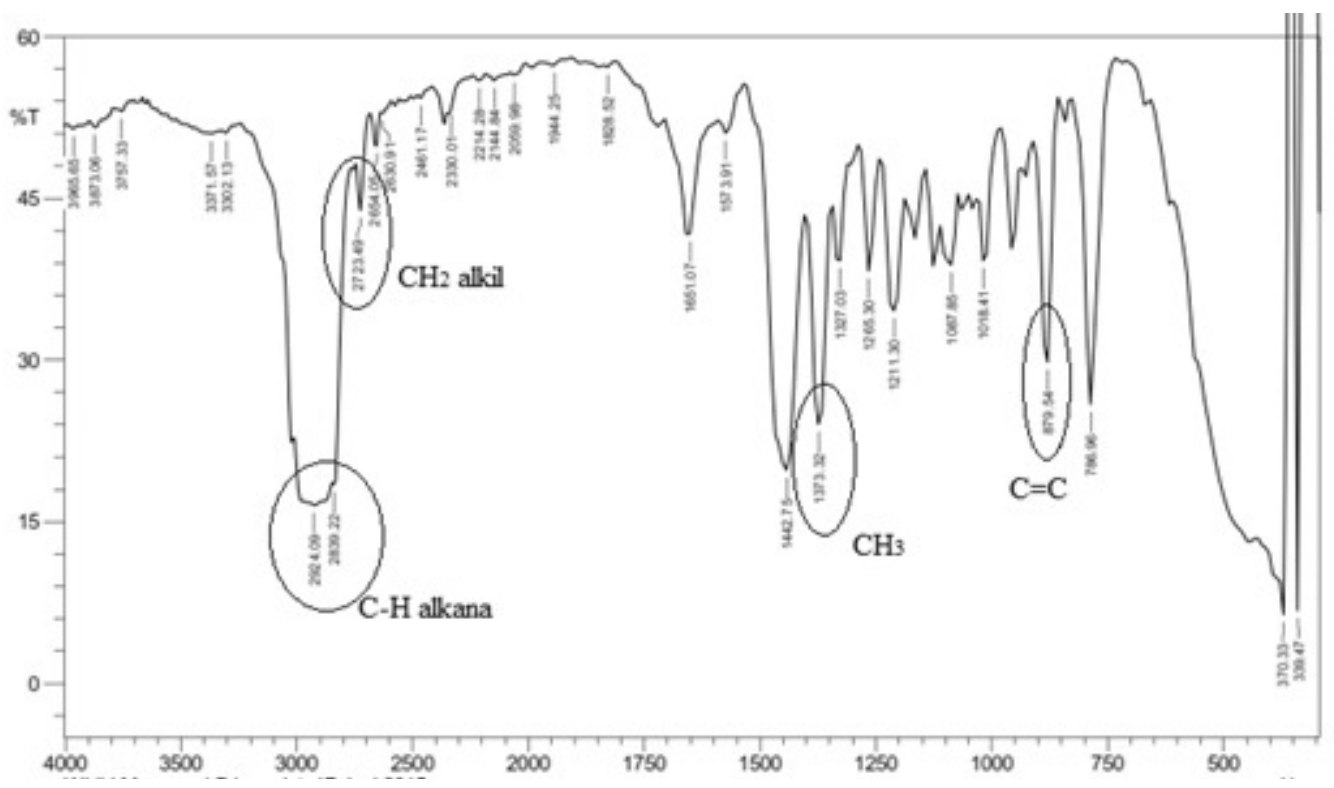

Gambar 3. IR Spectrum product of $\alpha$-pinene isomerization

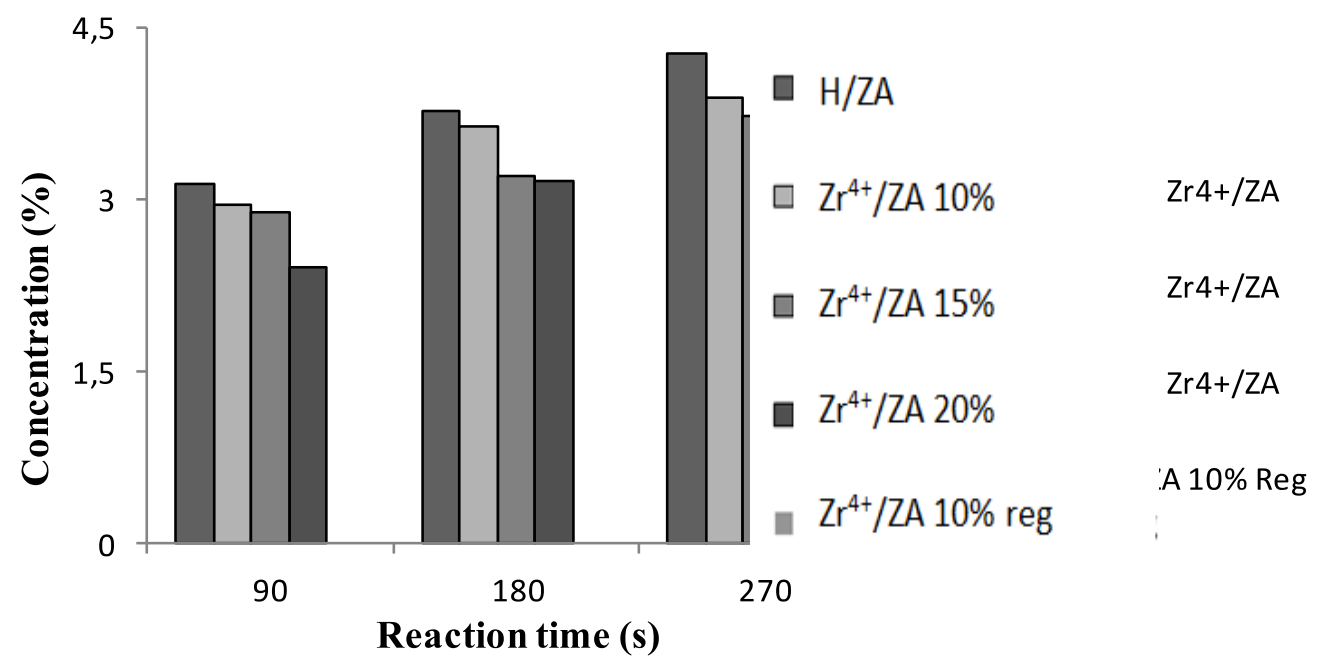

Figure 4. The Presented of $\alpha$-Pinena conversion with $\mathrm{H} / \mathrm{ZA}$ and $\mathrm{Zr}^{4+} / \mathrm{ZA}$

according to the characteristics $\alpha$-pinene while uptake $\mathrm{CH}_{2}$ alkyl and $\mathrm{C}=\mathrm{C}$ at the outer ring isomer in accordance with the characterization of $\alpha$-pinene.

Results of the conversion of $\alpha$-pinene was analyzed by Gas Chromatography. $\alpha$-Pinene conversion results are presented in Figure 4.

Based on Figure 4, it is known that there is the greatest conversion catalyst $\mathrm{Zr}^{4+} / \mathrm{ZA} 10 \%$. In the span of 90,180 and 270 minutes produced greater conversion than the catalyst $\mathrm{Zr}^{4+} / \mathrm{ZA}$
15 and $20 \%$. This happens because the metal catalyst dropped on $\mathrm{Zr}^{4+} / \mathrm{ZA} 10 \%$ is the largest of the three catalysts used for the reaction. So that more metal is teremban expected reaction will run more and more. However, as a result of conversion comparators that $\alpha$-pinene with $\mathrm{Zr}^{4+} / \mathrm{ZA} 10 \%$ compared with $\mathrm{H} / \mathrm{ZA}$ so far the greater conversion results with $\mathrm{H} / \mathrm{ZA}$. This is likely due to the larger value of acidity (6 $\mathrm{mmol} / \mathrm{g}: 3 \mathrm{mmol} / \mathrm{g}$ ) as isomerization runs on an acid catalyst so that when the value of acidity is 
more powerful then the result of the conversion of $\alpha$-pinene will be greater. Therefore catalyst $\mathrm{Zr}^{4+} / \mathrm{ZA} 10 \%$ which resulted in the highest conversion reusabiltasnya then regenerated to be tested against $\alpha$-pinene isomerization reaction with the conditions the best results.

Results of $\alpha$-pinene conversion with catalyst $\mathrm{Zr}^{4+} / \mathrm{ZA} 10 \%$ regeneration yield \%conversion is $4.26 \%$ greater than the catalyst $\mathrm{Zr}^{4+} / \mathrm{ZA} 10 \%$ which only amounted to $3.89 \%$. The reason for these results because the acidity $\mathrm{Zr}^{4+} / \mathrm{ZA} 10 \%$ regeneration greater than $\mathrm{Zr}^{4+} / \mathrm{ZA} 10 \%$ and also mean the average pore sizes of the catalyst $\mathrm{Zr}^{4+}$ ZA $10 \%$ regeneration bigger 84.8 points of the catalyst $\mathrm{Zr} 4+/ \mathrm{ZA} 10 \%$ based on Table 3 . So that contact between $\alpha$-pinene with $\mathrm{Zr}^{4+}$ cation form $\mathrm{Zr}^{4+}$ ions and natural zeolite have maximal.

Alfa-pinene conversion results tend small that only $<4.5 \%$ due to the acidity of the catalyst is small. In this study, the acidity of the catalyst is only about $1-4 \mathrm{mmol} / \mathrm{g}$, in contrast with study of J.-J Zou et al (2012) that found a high acidity that is $>10 \mathrm{mmol} / \mathrm{g}$. So that could be taken because that $\alpha$-pinene isomerization reaction be run either on a compound isomers acidity $>10 \mathrm{mmol} / \mathrm{g}$.
Isomerization reaction product of $\alpha$-pinene in this study is kamfena and limonena. The concentration of the compound kamfena depiction isomerization reaction proceeds $\alpha$-pinene is presented in Figure 5 .

Based on Figure 5, kamfena the largest concentration resulting from the reaction product with the catalyst $\mathrm{Zr}^{4+} / \mathrm{ZA} 10 \%$. However the reaction time of 90 minutes is the largest concentration of products kamfena reaction product with the catalyst $\mathrm{Zr}^{4+} / \mathrm{ZA} 15 \%$. The reason for these results together with the reason of the conversion of $\alpha$-pinene that $\mathrm{Zr}^{4+} / \mathrm{ZA} 10 \%$ catalyst have values higher acidity and levels dropped $\mathrm{Zr}^{4+}$ cations better than $\mathrm{Zr}^{4+} / \mathrm{ZA} 15 \%$ catalyst. While $\mathrm{Zr}^{4+} / \mathrm{ZA} 10 \%$ regeneration produce value of $0.82 \%$. The result was smaller with the reaction product with the catalyst $\mathrm{Zr}^{4+} / \mathrm{ZA} 10 \%$ to reach $0.93 \%$. The reason of more small products are compounds kamfena are compounds bicyclic formation process based on the strength of a Lewis acid, though $\mathrm{Zr} 4+/ \mathrm{ZA} 10 \%$ regeneration has a value of acidity higher $0.2 \mathrm{mmol} / \mathrm{g}$ of catalyst $\mathrm{Zr}^{4+} /$ ZA $10 \%$ but the levels of cation $\mathrm{Zr}^{4+}$ the catalyst $\mathrm{Zr}^{4+} / \mathrm{ZA} 10 \%$ higher than dropped to $\mathrm{Zr}^{4+} / \mathrm{ZA} 10 \%$ regeneration. Therefore dropped metal has more

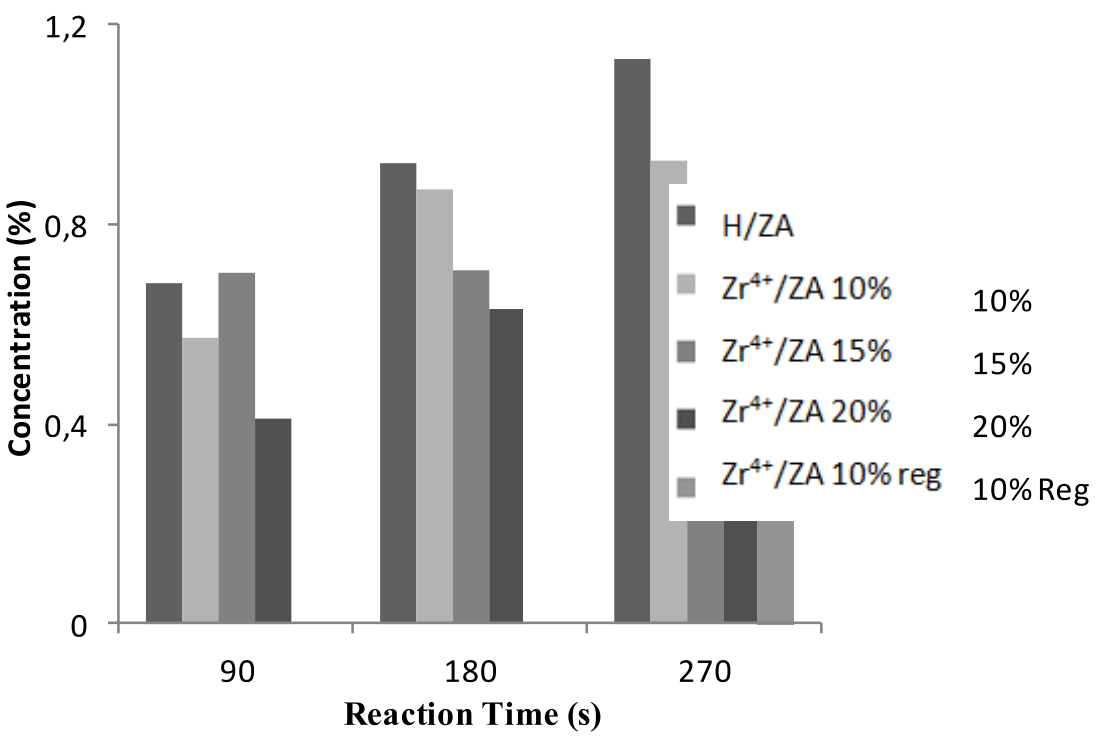

Figure 5.The Presented of camphene concentration isomerization product results with $\mathrm{H} / \mathrm{ZA}$ and $\mathrm{Zr}^{4+} / \mathrm{ZA}$ 


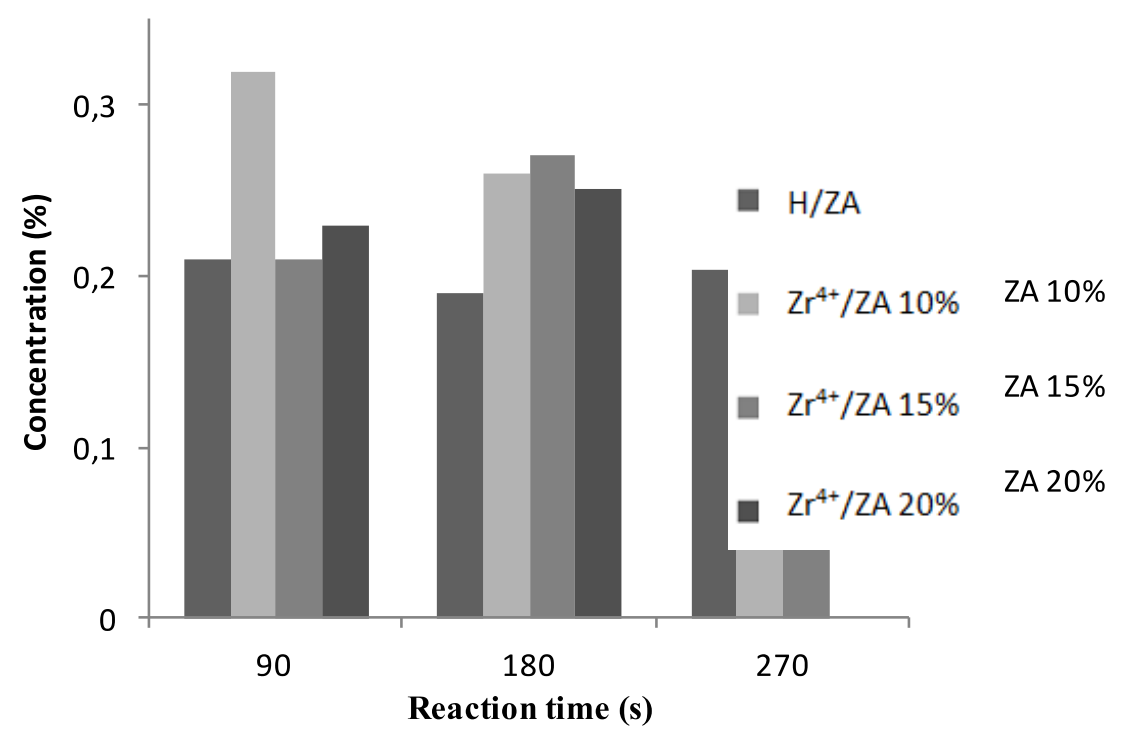

Figure 6.The Presented of camphene concentration isomerization product results with $\mathrm{H} / \mathrm{ZA}$ and $\mathrm{Zr}^{4+} / \mathrm{ZA}$

contribute more Lewis acid sites on the catalyst so that the catalyst $\mathrm{Zr}^{4+} / \mathrm{ZA} 10 \%$ who have a larger metal having Lewis acid sites greater. While the depiction of compound concentration limonena results $\alpha$-pinene isomerization reactions are presented in Figure 6.

Based on Figure 6, The presented of concentration limonena isomerization reaction result isn't constan of either an increase or decline. Limonena compound concentration on reaction time of 90 minutes indicated that the catalyst $\mathrm{Zr}^{4+} / \mathrm{ZA} 10 \%$ of the largest is $0.32 \%$. However the reaction time of 180 minutes, the catalyst $\mathrm{Zr}^{4+} / \mathrm{ZA} 15 \%$ has the highest limonena product is $0.27 \%$ and the reaction time of 270 minutes catalyst $\mathrm{Zr}^{4+} / \mathrm{ZA} 10 \%$ limonena has the biggest concentration is $0.24 \%$. While the catalyst $\mathrm{Zr}^{4+} / \mathrm{ZA} 10 \%$ regeneration limonena didn'tt shown great results so it isn't readable by gas chromatography (GC). Limonena product itself is a monocyclic compound formed from the reaction of isomerization of $\alpha$-pinene from contact with Brønsted acid sites. But in this study should levels largest limonena owned by $\mathrm{H} / \mathrm{ZA}$ is used as a comparison because it has Brønsted acid sites.

\section{CONCLUSION}

Catalysts $\mathrm{Zr}^{4+} / \mathrm{ZA} 10 \%$ were prepared as isomerization $\alpha$ - pinene showed the best results in the conversion of $\alpha$ - pinene is as much as $3.89 \%$ compared with the catalyst $\mathrm{Zr}^{4+} / \mathrm{ZA} 15 \%$ and $20 \%$. However, after the catalyst catalyst $\mathrm{Zr}^{4+} / \mathrm{ZA} 10 \%$ regenerated conversion results showed $\alpha$ - pinene becomes larger, ie $4.26 \%$. While the largest concentration of compounds in the product of the isomerization is the compound p-simena almost throughout variation of the catalyst and reaction time. Results of other compounds are kamfena product, 3-carene, ß-pinene, and limonena.

\section{REFERENCES}

Agustina, M., E, Kusuma., and Sudarmin 2013. Activity Test in Product of $\alpha$-pinene hydration Toward Bacillus cereus. Indo J. Chem. Sci. 2 (2): 136-141.

Comelli, N.A, E. N. Ponzi, M. I. Ponzi. 2005.

"Isomerization of $\alpha$-Pinene, Limonene, $\alpha$-terpinene, and Terpinolene on sulfated Zirconia". JAOCS. 82: 531-535

Witanto, E. and W. Trisunaryanti. 2010.

Preparation and Characterization of 
Catalysts Ni-Mo /Active Natural Zeolite. National Seminar on HR VI NUCLEAR TECHNOLOGY, -

Grzona, L., N. Comelli, O. Masini, E. Ponzi. 1999 "Liquid Phase isomerization of alphapinene Study of the Reaction in sulfated ZrO2".Akademiai Kiado, 69, (2), 271-276.

Perum Perhutani. 201. Annual Report Perhutani, Accessed on 12 Juli 2015 via http://perumperhutani.com/wpcontent/ uploads/2013/07/ARA_Perhutani_2014_ LOW.pdf

Trisunaryanti, W., E. Triwahyuni., And S. Sudiono. 2005. Preparation, Modification and Characterization of Catalysts Ni-Mo / Zeolite and Mo-Ni / Zeolite. TEKNOI 10 (4): 269-282.
Trisunaryanti, W., Triyono, and F. Taufiyanti. 2002. Catalyst Deactivation and Regeneration Cr / Active Natural Zeolite for the Conversion Process Methyl isobutyl ketone. Gama Science, 4 (2): 142-14.

Wijayati, N. 2014. Synthesis of $\alpha$-Terpineol Through Hydration $\alpha$-pinene With Homogeneous Catalysts (SA, MCA, TCA) and Heterogeneous (ZHY, TCA / ZHY) Activity Test And $\alpha$-Terpineol As Antibacterial substances. Dissertation. Yogyakarta: Gadjah Mada University.

Wiyono, B., S. Tachibana, and D. Tinambuan. 2006. Chemical Composition of Indonesia Pinus Turpentine Oil, Gum Oleoresins and Rosins from Sumatra and Java. Pakistan Journal of Biological Sciences, 9 (1): 7-14 